\title{
PENELITIAN BIOLIMNOLOGI SUMBER DAYA PERAIRAN BARU BEKAS TAMBANG TIMAH DI PULAU BANGKA DAN BELITUNG UNTUK BUDI DAYA IKAN
}

\author{
Samuel ${ }^{*}$, Azwar Said ${ }^{*}$ dan Siti Nurul Aida*
}

\begin{abstract}
ABSTRAK
Penelitian biolimnologi pada kolong-kolong bekas tambang timah di Pulau Bangka dan Pulau Belitung telah dilakukan pada tahun 1995. Penelitian bertujuan mendapatkan data biolimnologi meliputi parameter fisika, kimia dan biologi guna menilai kelayakan perairan sebagai tempat usaha perikanan. Penelitian dilaksanakan dengan metode survai pada beberapa kolong yang dipilih berdasarkan umur yakni kolong baru: 0-5 tahun, kolong muda: $5 \cdot 20$ tahun dan kolong tua: di atas 20 tahun.

Hasil penelitian menunjukkan bahwa kolong baru belum layak digunakan untuk usaha perikanan. Pada kolong muda dan lama, parameter limnologinya seperti suhu, kecerahan, kedalaman, $\mathrm{pH}$, oksigen terlarut dan karbondioksida bebas memberikan penilaian dengan kondisi air yang layak untuk tempat hidup ikan. Beberapa parameter seperti kandungan fosfat, nitrogen total, alkalinitas, kesadahan, sulfat, kalsium dan magnesium serta jumlah fitoplankton memberikan penilaian perairan dengan tingkat kesuburan rendah. Dengan kondisi perairan demikian disimpulkan ikan dapat hidup tetapi kurang mendukung untuk tumbuh dan berkembang biak secara optimal.
\end{abstract}

ABSTRACT: Biolimnological study on tin mining pools in the islands of Bangka and Belitung for aquaculture. By: Samuel, Azwar Said and Siti Nurul Aida.

Biolimnological study of abandoned tin mining pools was carried out in Bangka and Belitung islands in 1995. The objective of the study was to evaluate the biolimnological characteristics and suitability of the pools for fish culture. Observations were conducted by survey method on some abandoned tin mining pools selected based on the age of the pools as: new (0-5 years), medium (5-20 years) and old (more than 20 years).

Biolimnological parameters collected and examined from the sites showed that the water condition of the new pools was unsuitable for fish culture. However, for medium and old pools, based on several water parameters such as: temperature, transparency, depth, $p H$, dissolved oxygen $\left(O_{2}\right)$ and carbondioxyde $\left(C O_{0}\right)$ indicated that the water was suitable. Based on other parameters such as: phosphate $\left(\mathrm{PO}_{4}\right)$, total nitrogen, alkalinity, hardness, sulphate $\left(\mathrm{SO}_{4}\right)$, calcium $(\mathrm{Ca})$, magnesium $(\mathrm{Mg})$ and phytoplankton content, the waters can be classified as oligotrophic. In the condition above the fish could live, however, the growth rate was slow and the reproduction was not in optimal condition.

\section{KEYWORDS: biolimnology, aquatic resource, tin mining pools.}

\section{PENDAHULUAN}

Kolong adalah perairan yang berbentuk kolam yang luas atau dapat juga berbentuk danau atau waduk bekas aktivitas penambangan bahan galian. Khusus di Pulau Bangka dan Pulau Belitung, kolong-kolong terjadi akibat adanya aktivitas penambangan timah sehingga terbentuklah cekungan yang luas dan tergenang. Berdasarkan umurnya, kolong-kolong dapat dibedakan antara kolong baru, kolong muda dan kolong tua, dengan umur masingmasing kurang dari lima tahun, antara 5-20 tahun dan di atas 20 tahun.

Pada tahun 1995 kolong-kolong bekas galian tambang timah di Pulau Bangka luasnya mencapai
15.869 hektar atau sekitar 1,38\% dari luas Pulau Bangka (1.15().280 hektar), sedangkan luas areal penambangan PT Timah ada sekitar 538.326 hektar atau sekitar 46\% luas daratan Pulau Bangka (Anonim, 1991). Areal penambangan tersebut oleh PT Timah disebut area of interest yang terdiri atas wilayah eksplorasi, wilayah cadangan, wilayah kerja dan wilayah bekas penambangan.

Terlepas dari wilayah-wilayah tersebut, perhatian dari subsektor perikanan adalah bagaimana memanfaatkan perairan di kolong-kolong bekas galian tambang timah tersebut agar dapat digunakan untuk budi daya ikan.

*) Peneliti pada Loka Penelitian Perikanan Air Tawar Palembang 
Penelitian ini bertujuan untuk mendapatkan data dan informasi biolimnologi perairan pada kolong-kolong bekas galian tambang timah di Pulau Bangka dan Pulau Belitung sebagai data dasar untuk budidaya ikan.

\section{METODE PENELITIAN}

Penelitian dilakukan dengan metode survai dengan pengumpulan data dan informasi melalui tiga cara yaitu 1) pengamatan dan pengukuran parameter di lapang, 2) analisis laboratorium dan 3) pengumpulan data sekunder dari P'T Timah. Penelitian dilaksanakan pada bulan-bulan Mei, Agustus, Oktober dan Desember 1995. Lokasi kolong-kolong tempat pengambilan sampel dapat dilihat pada Gambar 1, sedangkan nama kolong, luas, umur dan status tertera pada Tabel 1.

Pengambilan contoh air pada kolong dibagi menjadi dua cara: 1) secara horisontal di bagian tengah perairan dan 2) secara vertikal, yaitu a) di bagian antara permukaan-batas kecerahan dan b) di bagian dasar perairan. Metode dan alat yans digunakan dalam pengukuran parameter ('l'abel 2) berpedoman pada buku petunjuk yang dikemukakan oleh APHA (1981) dan Boyd (1979). Untuk sampel tanah diambil pada bagian tepi dan dasar kolong-kolong, parameter yang diperiksia terdiri atas $\mathrm{pH}$, kapasitas tukar kation, Al-dapat ditukar (A]-exchangeable), $\mathrm{SO}, \mathrm{Fe}, \mathrm{P}$-tersedia dan tekstur. Sampel tanah dianalisis di laboratorium.

Keadaan cuaca untuk Pulau Bangka dan P'ulau Belitung menunjukkan bahwa curah hujan hampil merata sepanjang tahun sehingga tidak pernah mengalami bulan kering dan bahkan hari hujan pada musim kemarau pun mendekati 10 hari per bulan (Anonim, 1991). Keadaan kolong selalu tergenang oleh air meskipun musim kemarau sehingga air dalam kolong selalu tersedia. Suhu udara rata-rata bulanan berkisar antara $2.5 \cdot 27^{\circ} \mathrm{C}$. suhu minimum terendah $21^{\circ} \mathrm{C}$ terjadi pada bulan Juli dan September. Suhu maksimum tertingsi yang pernah tercatat adalah $34^{\circ} \mathrm{C}$ terjadi pada bulan Oktober.

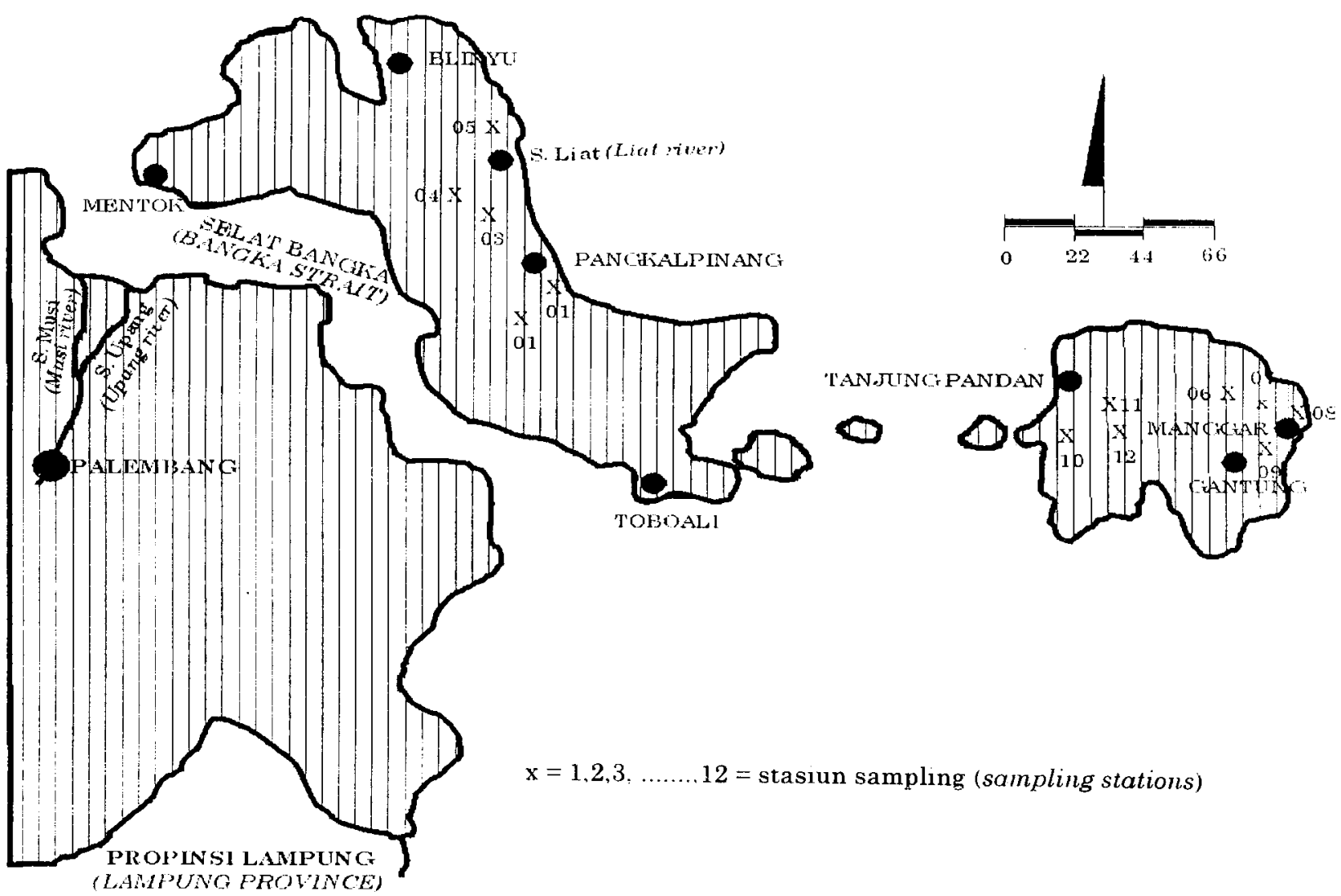

Gambar 1. Stasiun sampling biolimnologi pada kolong-kolong bekas tambang di Pulau Bangkia dan Pulau Belitung, Sumatera Selatan. (Keterangan lebih lanjut dapat dilihat padal Tabel 1.)

Figure 1. Sampling stations of biolimnology on the abandoned tin mining pools in Banghu dun Beliung Islands, South Sumatera. (Further information are depicted in Table 11 
Tabel 1. Stasiun penelitian biolimnologi pada kolong-kolong bekas tambang timah di Pulau Bangka dan Pulau Belitung.

Table 1. Sampling stations of biolimnology on the abandoned tin mining pools in Bangka and Belitung islands.

\begin{tabular}{lcclc}
\hline \multicolumn{1}{c}{$\begin{array}{c}\text { Nama } \\
\text { Name }\end{array}$} & $\begin{array}{c}\text { Daerah } \\
\text { Area } \\
\text { (ha) }\end{array}$ & $\begin{array}{c}\text { Umur (th) } \\
\text { Age (year) }\end{array}$ & \multicolumn{1}{c}{$\begin{array}{c}\text { Klasifikasi } \\
\text { Classification }\end{array}$} & $\begin{array}{c}\text { Lokasi } \\
\text { Location }\end{array}$ \\
\hline Lampor & 3 & 3 & Kolong baru (New pool) & Bangka \\
K- 25 & 5 & 8 & Kolong muda (Medium pool) & Bangka \\
TS-136 & 4 & 10 & Kolong muda (Medium pool) & Bangka \\
Pemali & 4 & 28 & Kolong tua (Old pool) & Bangka \\
Jeliti & 4 & 25 & Kolong tua (Old pool) & Bangka \\
Mempayau & 4 & 12 & Kolong muda (Medium pool) & Belitung \\
Air Mang & 10 & 42 & Kolong tua (Old pool) & Belitung \\
Air Keroh & 6 & 15 & Kolong muda (Medium pool) & Belitung \\
L.Golf L. & 4 & 17 & Kolong muda (Medium pool) & Belitung \\
Tilang & 4 & 17 & Kolong muda (Medium pool) & Belitung \\
TS-12A & 3 & 5 & Kolong baru (New pool) & Belitung \\
TK-13 & 4 & 16 & Kolong muda (Medium pool) & Belitung \\
\end{tabular}

\section{HASIL DAN BAHASAN}

\section{Kesuburan Tanah}

Hasil analisis parameter fisika dan kimia tanah tertera pada Tabel 3. Dari Tabel 3 terlihat bahwa parameter kesuburan tanah terdiri atas $\mathrm{pH}$, kapasitas tukar kation (KTK), Al-dapat ditukar (Aldd), sulfat ( $\mathrm{SO} 4)$, besi $\left(\mathrm{Fe}^{+}\right)$, P-tersedia dan tekstur menggambarkan tingkat kesuburan tanah yang rendah (Pusat Penelitian Tanah, 1981 dalam Anonim, 1991). Potensi kesuburan tanah Pulau Bangka tercermin dari faktor pembentuk tanahnya, terutama sifat-sifat batuan, mineral, iklim dan umur pembentukannya (Anonim, 1991). Tanah-tanah dari proses pelapukan batuan granit umumnya bersifat masam dengan kandungan $\mathrm{SiO}_{2}$ lebih dari $65 \%$, sedangkan pelapukan dari batuan intermedier (diorit) dan batuan basalt (dolerit) hanya terdapat dalam jumlah yang sangat terbatas. Di Pulau Bangka juga banyak terdapat batuan sedimen dan endapan aluvial hasil proses pelapukan dan pengikisan dan bahan tersebut bertekstur kasar (pasir kuarsa, konkresi besi dan sedikit liat). Tanah-tanah di Pulau Bangka umumnya terbentuk dari hasil pelapukan granit yang menghasilkan tanah-tanah bertekstur kasar dengan kadar pasir silikat sangat tinggi. Tanah tersebut relatif tidak mengandung mineral-mineral dan mudah lapuk sehingga cadangan unsur-unsur hara yang dapat cepat dipakai tanaman sangat kecil sehingga pada dasarnya tanah tersebut tidak subur (Anonim, 1991). Tanah di Pulau Bangka mempunyai reaksi yang sangat masam $(<\mathrm{pH} 4,5)$ dengan kapasitas tukar kation (KTK) dan kandungan sejumlah basa-basa $(\mathrm{Ca}, \mathrm{Mg}, \mathrm{K}$ dan $\mathrm{Na}$ ) sangat rendah, sedangkan kejenuhan $\mathrm{Al}$ sangat tinggi (>60\%), sehingga disimpulkan bahwa secara alamiah potensi kesuburan tanah di Pulau Bangka tergolong sangat rendah (Pusat Penelitian Tanah, 1987 dalam Anonim, 1991). Tanah yang demikian pada dasarnya tidak sesuai untuk usaha pertanian.

\section{BIOLIMNOLOGI PERAIRAN}

Hasil pengukuran parameter kualitas air dan kandungan logam berat pada beberapa kolong pengamatan dapat dilihat pada Tabel 4 dan Tabel 5 , dan secara rinci dikemukakan sebagai berikut.

Kolong Baru. Yang termasuk kolong baru ada dua, yaitu (01) Kolong Lampor dan (11) Kolong TS12A. Keasaman air kedua perairan tersebut rendah yaitu 4,2-5,5 (air bersifat asam), termasuk kisaran yang tidak layak untuk kehidupan ikan (NTAC, 1968; Pescod, 1973; Swingle, 1968 dan Ellis, 1937 dalam Boyd, 1979). Suhu, kecerahan dan kedalaman masih dalam kisaran yang baik untuk mendukung kehidupan ikan (Cuchlaine, 1975). Kandungan oksigen dan karbondioksida masih dalam kadar yang layak untuk hidup ikan (N'TAC, 
Tabel 2. Parameter kualitas air dan metode pengukurannya.

Table 2. Water quality parameters and methods.

\begin{tabular}{|c|c|c|}
\hline Parameter & Unit & Metode (Methods) \\
\hline \multicolumn{3}{|l|}{ Fisik (Physical): } \\
\hline Suhu (Temperature) & ${ }^{\circ} \mathrm{C}$ & 'Thermometer \\
\hline Kecerahan (Transparency) & $\mathrm{cm}$ & Secchi dish \\
\hline Kedalaman (Depth) & $\mathrm{m}$ & Staff gauge \\
\hline \multicolumn{3}{|l|}{ Kimiawi (Chemical): } \\
\hline $\mathrm{pH}$ & & Universal Indicator \\
\hline DO & $\mathrm{mg} / \mathrm{L}$ & 'Titrimetri \\
\hline $\mathrm{CO}_{2}$-bebas $\left(\mathrm{CO}_{2}\right.$-free $)$ & $\mathrm{mg} / \mathrm{L}$ & Titrimetri \\
\hline Alkalinitas (Alkalinily) & $\mathrm{mg} / \mathrm{L}$ & Titrimetri \\
\hline Kesadahan (Hardness) & $\mathrm{mg} / \mathrm{L}$ & 'Titrimetri \\
\hline $\mathrm{NH}_{3}-\mathrm{N}$ & $\mathrm{mg} / \mathrm{L}$ & Spectrophotometer \\
\hline $\mathrm{NO}_{3}-\mathrm{N}$ & $\mathrm{mg} / \mathrm{L}$ & Spectrophotometer \\
\hline $\mathrm{NO}_{2}-\mathrm{N}$ & $\mathrm{mg} / \mathrm{L}$ & Spectrophotometer \\
\hline $\mathrm{PO}_{1}-\mathrm{P}$ & $\mathrm{mg} / \mathrm{L}$ & Spectrophotometer \\
\hline $\mathrm{SO},-\mathrm{P}$ & $\mathrm{mg} / \mathrm{L}$ & Spectrophotometer \\
\hline \multicolumn{3}{|l|}{ Elemen metal (Metal Element) } \\
\hline $\mathrm{Pb}$ & $\mathrm{mg} / \mathrm{L}$ & AAS \\
\hline $\mathrm{Hg}$ & $\mathrm{mg} / \mathrm{L}$ & AAS \\
\hline $\mathrm{Cd}$ & $\mathrm{mg} / \mathrm{L}$ & AAS \\
\hline $\mathrm{Cu}$ & $\mathrm{mg} / \mathrm{L}$ & AAS \\
\hline $\mathrm{Al}$ & $\mathrm{mg} / \mathrm{L}$ & AAS \\
\hline $\mathrm{Fe}$ & $\mathrm{mg} / \mathrm{L}$ & Spectrophotometer \\
\hline $\mathrm{Mg}$ & $\mathrm{mg} / \mathrm{L}$ & Spectrophotometer \\
\hline $\mathrm{Ca}$ & $\mathrm{mg} / \mathrm{L}$ & Spectrophotometer \\
\hline \multicolumn{3}{|l|}{ Biologi (Biological): } \\
\hline Ikan (Fish) & & Gillnet \\
\hline Plankton & ind./L & Plankton net no. 25 \\
\hline Org. benthos (Benthic org.) & ind. $/ \mathrm{m}^{2}$ & Ekman dredge \\
\hline Tanaman air (Aquatic plants) & & Visual in situ \\
\hline
\end{tabular}

1968: Swingle, 1968). Alkalinitas, kesadahan, kadar nitrogen total, fosfat dan sulfat adalah rendah (Boyd, 1979; Swingle, 1968; Parma, 1980; Pescod, 1973). Mereka mengklasifikasikan perairan tersebut ke dalam tingkat kesuburan rendah. Kadar logam berat di bagian permukaan untuk $\mathrm{Pb}$, $\mathrm{Hg}$ dan $\mathrm{Cu}$ tergolong tinggi, sedangkan $\mathrm{Cd}$ rendah. Di bagian dasar kolong-kolong kandungan logam berat $\mathrm{Pb}, \mathrm{Cd}$ dan $\mathrm{Cu}$ tergolong tinggi (Pescod, 1973) sehingga tidak layak untuk kehidupan ikan. Kadar khlorofil-a pada permukaan perairan masing. masing kolong adalah $14,7 \mathrm{dan} 17,0 \mathrm{mg} / \mathrm{m}^{*}$. Perairan ini termasuk tingkat kesuburan sedang atau mesotrofik (Wetzel, 1975).

Kolong yang tergolong dalam kelompok kolong baru ditinjau dari parameter kualitas airnya sebagaimana diterangkan di atas, kurang layak untuk usaha budi daya. Meskipun ikan dapat hidup karena kadar oksigen dan karbondioksida yang layak untuk kehidupan ikan, namun kadar logam berat yang masih tinggi baik di dasar maupun di permukaan akan dapat membahayakan kcischatan ikan dan kessehatan manusia yang mengkunsumsinya.

Kolong Muda. Yang termasuk kolong muda ada tujuh. vaitu (02) Kolong K-25. (03) T'S- 136. (06) Mempayau. (08) Air Keroh. (09) L.Golf L.. (10) Tilang dan (12) Kolong TK-13. Parameter kualitas: air terdiri atas suhu, kecerahan, kedalaman. pH. oksigen dan karbondioksida tergolong clalam kisaran yang kurang layak untuk kehidupan ikan. Dari beberapa parameter kesuburan antara lain 
Tabel 3. Kualitas tanah dari kolong-kolong penelitian di Bangka 1995

Table 3. Soil quality obtained from tin mining pools in Bangka in 1995.

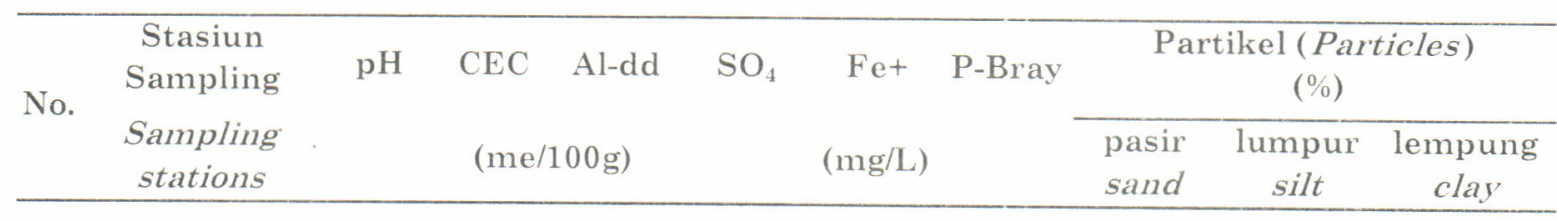

A. Tanah dasar (Bottom soils):

$\begin{array}{lrrrrrrrrr}\text { 1. Kolong lampor } & 3.9 & 9.58 & 9.02 & 79.04 & 48.75 & 3.60 & 40.33 & 37.66 & 22.01 \\ \text { 2. Kolong K.25 } & 5.6 & 16.16 & 1.34 & 0.76 & 9.75 & 2.10 & 16.06 & 26.28 & 57.06 \\ \text { 3. Kolong TS.136 } & 5.8 & 14.96 & 6.07 & 144.40 & 6.83 & 3.30 & 28.62 & 55.83 & 15.55 \\ \text { 4. Kolong Pemali } & 5.4 & 9.52 & 1.60 & 36.48 & 0.88 & 2.40 & 15.62 & 39.43 & 44.95 \\ \text { 5. Kolong Jelita } & 5.7 & 2.17 & 0.00 & 1.52 & 0.10 & 6.00 & 100 & 0.00 & 0.00\end{array}$

B. Tanah pinggir (Edge soils):

\begin{tabular}{lrrrrrrrrr} 
1. Kolong lampor & 4.0 & 8.70 & 7.99 & 121.60 & 2.44 & 3.86 & 60.07 & 12.94 & 26.99 \\
2. Kolong K.25 & 5.2 & 8.98 & 0.80 & 16.75 & 0.10 & 4.02 & 60.82 & 6.35 & 32.83 \\
3. Kolong TS.136 & 6.3 & 15.23 & 0.00 & 27.36 & 0.10 & 6.46 & 27.09 & 12.32 & 60.59 \\
4. Kolong Pemali & 5.1 & 9.52 & 1.61 & 17.48 & 0.78 & 3.98 & 45.92 & 19.07 & 35.01 \\
5. Kolong Jelita & 5.6 & 6.00 & 0.00 & 0.84 & 0.12 & 4.82 & 82.83 & 10.08 & 7.09 \\
\hline
\end{tabular}

alkalinitas, kesadahan, nitrogen total, fosfat dan sulfat menggolongkan perairan dengan tingkat kesuburan rendah. Kadar logam berat $\mathrm{Pb}, \mathrm{Hg}$ dan Cd di bagian permukaan masih di bawah nilai ambang batas dan termasuk belum membahayakan bagi kesehatan ikan (Pescod, 1973). Kadar Cu di bagian permukaan dan $\mathrm{Pb}, \mathrm{Hg}$, Cd dan $\mathrm{Cu}$ di bagian dasar tergolong tinggi.

Pada kolong yang termasuk dalam klasifikasi kolong muda, beberapa parameter kualitas airnya seperti suhu, kecerahan, kedalaman, pH, oksigen dan karbondioksida masih dalam kisaran yang layak untuk kehidupan ikan tetapi dari beberapa parameter seperti alkalinitas, kesadahan, nitrogen total, fosfat, sulfat, magnesium dan kalsium, perairan kolong muda tergolong tidak subur. Kandungan logam berat di bagian permukaan rendah kecuali Cu dan Hg. Untuk kolong yang demikian pemeliharaan ikan dalam keramba atau jaring. jaring terapung pada lapisan air di bagian permukaan dapat dilakukan. Monitoring terhadap kandungan logam berat terutama $\mathrm{Cu}$ dalam jaringan tubuh ikan perlu dilakukan agar diketahui apakah ikan tergolong layak atau tidak untuk dikonsumsi.

Kolong Tua. Yang termasuk kolong tua dalam penelitian ini ada tiga, yaitu (04) Pemali, (05) Jeliti dan (07) Air Mang. Dilihat dari beberapa parameter kualitas airnya dan kandungan logam berat, tidak jauh berbeda dengan kondisi kualitas air pada kolong-kolong muda. Suhu, kecerahan, kedalaman, pH, oksigen dan karbondioksida menggolong. kan perairan layak untuk hidup ikan tetapi perairan tetap kurang subur. Demikian pula dari kandungan logam berat $\mathrm{Pb}, \mathrm{Hg}$ dan $\mathrm{Cd}$ di bagian permukaan sudah di bawah nilai ambang batas (Pescod, 1973) yang tidak membahayakan kehidupan ikan. Namun untuk kandungan logam berat $\mathrm{Cu}$ baik di bagian permukaan dan dasar perairan masih tinggi dan tetap perlu adanya monitoring lebih lanjut terutama kandungan logam berat dalam tubuh ikan bila kolong-kolong dimanfaatkan untuk memelihara ikan pada lapisan air di bagian permukaan.

Flora dan Fauna. Jenis-jenis organisme perairan yang diamati terdiri atas ikan, organisme dasar, plankton dan tumbuhan air. Untuk jenisjenis ikan, sebagaimana tertera pada Tabel 6 , di Kolong Lampor tertangkap ikan belida (Notopterus chitala) dengan panjang $52,5 \mathrm{~cm}$ dan bobot $880 \mathrm{~g}$. Dari kolong tersebut pernah juga tertangkap ikan baung (Mystus nemurus), gabus (Ophiocephalus striatus), lele (Clarias batrachus) dan gurame (Osphronemus goramy). Pada Kolong K-25 tidak tertangkap jenis ikan. Pada Kolong TS-136 penangkapan dengan jaring insang didapatkan jenis ikan bulan (Megalops cyprinoides). Menurut penduduk setempat pernah juga tertangkap ikan belida, gurame dan baung. Kolong Pemali pada waktu survai tidak didapatkan ikan, namun dari 
Tabel 4. Kualitas permukaan air kolong-kolong pengamatan.

Table 4. Water quality of waters surface of studied abandoned tin mining pools.

\begin{tabular}{|c|c|c|c|c|c|c|c|c|c|c|c|c|}
\hline \multirow{2}{*}{$\begin{array}{c}\text { Parameter } \\
\text { kualitas air } \\
\text { Water quality } \\
\text { parameters }\end{array}$} & \multicolumn{12}{|c|}{$\begin{array}{l}\text { Kolong-kolong bekas tambang } \\
\text { Abandoned tin mining pools }\end{array}$} \\
\hline & 1 & 2 & 3 & 4 & 5 & 6 & 7 & 8 & 9 & 10 & 11 & 12 \\
\hline \multicolumn{13}{|c|}{ A. Parameter fisik (Physical parameters): } \\
\hline $\begin{array}{l}\text { 1. Suhu } \\
\text { Temperature ("C) }\end{array}$ & 28.8 & 30.0 & 27.3 & 29.5 & $28 . \overline{5}$ & 27.0 & 28.0 & $2(t .0)$ & 29.0 & 29.0 & 28.11 & $2(4.1)$ \\
\hline $\begin{array}{l}\text { 2. Kecerahan } \\
\text { Transparncy }(\mathrm{cm})\end{array}$ & 210 & 107 & 130 & 97 & 1.50 & 100 & 120 & 110 & 150 & 110 & 125 & $2(x)$ \\
\hline \multicolumn{13}{|c|}{ B. Parameter kimiawi (Chemical parameter's): } \\
\hline 1. $\mathrm{pH}$ (units) & 4,2 & 6.7 & $(i .2$ & 6.0 & 5.7 & 6.5 & $(i .5)$ & 8.0 & 7.0 & 7.0 & $i . i$ & $\therefore .11$ \\
\hline 2. DO $(n g / L)$ & 8.06 & 8.69 & 8.32 & 7.90 & 8.37 & 7.20 & 7.30 & 7.20 & 7.30 & 7.00 & 7.20 & (i.ti) \\
\hline $\begin{array}{l}\text { 3. CO-bobils } \\
\text { ( }()_{\text {- freer }}(\mathrm{mg} / \mathrm{L})\end{array}$ & 9.50 & 5.07 & 6.86 & .5 .49 & (i. 19 & 9.12 & 7.20 & 3.26 & 3.26 & 3.41 & 8.46 & $\therefore 21$ \\
\hline $\begin{array}{l}\text { 4. Alkallinitals } \\
\text { Alkalinlty (mg/L) }\end{array}$ & ud & 10.74 & 9.12 & 10.57 & 4.56 & 15 & 16.5 & 42 & 13.3 & 12.5 & $3 . \overline{7}$ & 2.2 \\
\hline $\begin{array}{l}\text { 5. Kesadahan } \\
\text { Horduresis (mg/L) }\end{array}$ & ud & ud & ud & ud & ud & ud & ud & (60) & ud & ud & ud & ud \\
\hline 6. $\mathrm{NH}_{3}-\mathrm{N}(\mathrm{mg} / \mathrm{L})$ & 0.194 & 0.0 .56 & $0 .(1.5 .5$ & 0.115 & 0.128 & 0.093 & 0.080 & 0.091 & 0.090 & 0.077 & $0.07+$ & $0.094)$ \\
\hline 7. $\mathrm{NO}_{3} \cdot \mathrm{N}(\mathrm{mg} / \mathrm{L})$ & 0.140 & 0.127 & $0.1+13$ & 0.157 & 0.1 .33 & 0.133 & 0.133 & 0.144 & 0.144 & 0.133 & 0.122 & 0.102 \\
\hline 8. $\mathrm{NO}_{2} \cdot \mathrm{N}(\mathrm{mg} / \mathrm{L})$ & $0.30 \mathrm{i}$ & 0.318 & 0.312 & $0.30+4$ & 0.304 & 0.070 & 0.077 & 0.091 & 0.120 & 0.091 & $0.06(3)$ & 0.11911 \\
\hline 9. $\mathrm{PO} \cdot \mathrm{P}(\mathrm{mc} / \mathrm{L})$ & 0.0 .5 .3 & 0.049 & 0.0 .59 & 0.048 & 0.0 .46 & 0.078 & 0.078 & 0.070 & 0.049 & 0.078 & 0.107 & 0.178 \\
\hline 10. $S O_{1}-\mathrm{S}(\mathrm{mg} / \mathrm{L})$ & 0.237 & 0.234 & $0.22 ;$ & 0.228 & 0.233 & 0.174 & 0.174 & 0.164 & 0.164 & 0.174 & 0.164 & 11.174 \\
\hline \multicolumn{13}{|c|}{ 11. Elemen metal (Metal elemonts): } \\
\hline $\mathrm{Pb}(\mathrm{m} g / \mathrm{L})$ & 0.021 & 0.012 & 0.011 & 0.013 & 0.015 & -. & $(1.0669$ & 0.054 & 0.071 & -. & .. & -. \\
\hline$H_{g}(m g / L)$ & 0.004 & 0.001 & 0.000 .3 & 0.0016 & 0.01103 & .. & $(1.025$ & 0.0712 & 0.001 & -. & -. & -. \\
\hline $\mathrm{Cd}(m g / L)$ & 0.001 & 0.002 & 0.002 & 0.001 & 0.002 & -- & 0.003 & 0.004 & 0.001 & .. & -. & . \\
\hline $\mathrm{Cu}(\mathrm{m} g / \mathrm{L})$ & 0.048 & 0.026 & 0.037 & 0.026 & 0.030 & .. & 0.088 & 0.093 & 0.157 & .. & -. & -. \\
\hline$A \mid(m g / L)$ & 0.018 & 0.009 & 0.0127 & 0.027 & 0.024 & .. & 0.869 & 1091 & 0.987 & .. & .. & .. \\
\hline$F((m g / L)$ & 0.094 & 0.0 .53 & 0.100 & 0.218 & 0.154 & 0.094 & 0.085 & 0.067 & 0.076 & 0.094 & 0.0667 & 0.176 \\
\hline$M g(m g / L)$ & 0.607 & 0.778 & 0.55 .59 & 0.575 & 0.769 & 0.777 & 0.608 & 0.632 & 0.5599 & 0.827 & 0.608 & 0.632 \\
\hline$C_{i l}(m g / L)$ & 1.136 & 1.2 .56 & 1.149 & 1.122 & 1.094 & 1.122 & 1.042 & 1.041 & 1.202 & 1.40 .3 & 0.920 & 1.0102 \\
\hline \multicolumn{13}{|c|}{ C. Parameter biologi (Biological parameter): } \\
\hline $\begin{array}{l}\text { 1. Khlorofil } \\
\text { (Chlorofil (mo/L) }\end{array}$ & 1.4 .7 & 23.7 & 30.7 & 18.0 & 18.0 & 29.0 & 35.0 & 24.0 & 17.0 & 17.0 & $17.1)$ & 294.6 \\
\hline
\end{tabular}

Catatan (Rem(s)lss):

$01=\mathrm{l}$ ampor $0 \overline{\mathrm{s}}=\mathrm{j}$ eliti

$02=K \cdot 25 \quad 06=$ Mempayau

$03=$ TS-130; $07=$ Air Mang

$04=$ Pemali $08=$ Air Keroh
0 ) T.Golf $\quad$ ud $=$ tidak terukur (andelected $)$

$10=$ Tilang $--=$ tidak diambil simpel (no sample)

$11=\mathrm{TS} \cdot 12 \mathrm{~A}$

$12=\mathrm{T} K \cdot 13$ 
Tabel 5. Kualitas air di kolong-kolong pengamatan yang diambil dari bagian dasar perairan. Table 5. Water quality of bottom water of observed abandoned tin mining pools.

\begin{tabular}{|c|c|c|c|c|c|c|c|c|c|c|c|c|}
\hline \multirow{2}{*}{$\begin{array}{l}\text { Parameter } \\
\text { parameters }\end{array}$} & \multicolumn{12}{|c|}{$\begin{array}{c}\text { Kolong-kolong bekas tambang } \\
\text { Observed a bandoned tin mining pools }\end{array}$} \\
\hline & 1 & 2 & 3 & 4 & 5 & 6 & 7 & 8 & 9 & 10 & 11 & 12 \\
\hline \\
\hline $\begin{array}{l}\text { 1. Suhu } \\
\text { Temperature }\left({ }^{\circ} \mathrm{C}\right)\end{array}$ & 26.5 & 27 & 25 & 28 & 26.5 & 27 & 27.5 & 28 & 28 & 28 & 27.5 & 28 \\
\hline $\begin{array}{l}\text { 2. Kecerahan } \\
\text { Transparency }(\mathrm{cm})\end{array}$ & 4.2 & 4.7 & 5.7 & 3.8 & 3.1 & 4.0 & 7.0 & 8.0 & 6.0 & 5.0 & 7.0 & 6.0 \\
\hline \multicolumn{13}{|c|}{ B. Kimiawi (Chemical): } \\
\hline 1. $\mathrm{pH}$ (units) & 4.3 & 6.8 & 6.0 & 6.3 & 5.0 & 6.5 & 6.5 & 8.0 & 7.0 & 7.0 & 5.5 & 5.0 \\
\hline 2. $\mathrm{DO}(\mathrm{mg} / \mathrm{L})$ & 6.76 & 8.43 & 7.70 & $8 .(08$ & 7.42 & 6.56 & 7.04 & 5.96 & 6.86 & 5.90 & 6.30 & (6.40) \\
\hline \multirow{2}{*}{\multicolumn{13}{|c|}{$\begin{array}{l}\text { 3. } \mathrm{CO}_{2} \text {-bebas } \\
\mathrm{CO}_{2} \text {-free }(\mathrm{mg} / \mathrm{L})\end{array}$}} \\
\hline & & & & & & & & & & & & \\
\hline $\begin{array}{l}\text { 4. Alkalinitas } \\
\text { Alkalinity }(\mathrm{mg} / \mathrm{L})\end{array}$ & ud & 13.32 & 8.81 & 10.15 & 8.60 & 14.5 & 15.00 & 85.00 & 13.00 & 12.50 & 3.00 & 2.00 \\
\hline $\begin{array}{l}\text { 5. Kesadahan } \\
\text { Hardness }(\mathrm{mg} / \mathrm{L})\end{array}$ & ud & ud & ud & ud & ud & ud & ud & 60 & ud & ud & ud & ud \\
\hline 6. $\mathrm{NH}_{3}-\mathrm{N}(\mathrm{mg} / \mathrm{L})$ & 0.059 & 0.0 .58 & 0.057 & 0.060 & 0.059 & 0.083 & 0.090 & 0.074 & 0.090 & 0.085 & 0.088 & 0.080 \\
\hline 7. $\mathrm{NO}_{3}-\mathrm{N}(\mathrm{mg} / \mathrm{L})$ & 0.082 & 0.090 & 0.093 & 0.085 & 0.066 & 0.144 & 0.15 .5 & 0.102 & 0.133 & 0.144 & 0.139 & 0.128 \\
\hline 8. $\mathrm{NO}_{2}-\mathrm{N}(\mathrm{mg} / \mathrm{L})$ & 0.036 & 0.055 & 0.036 & 0.125 & 0.047 & 0.090 & 0.104 & 0.118 & 0.100 & 0.188 & 0.118 & 0.118 \\
\hline 9. $\mathrm{PO}_{4} \cdot \mathrm{P}(\mathrm{mg} / \mathrm{L})$ & 0.069 & 0.067 & 0.064 & 0.055 & 0.055 & 0.049 & 0.078 & 0.078 & 0.049 & 0.107 & 0.078 & 0.078 \\
\hline 10. $\mathrm{SO}_{4}-\mathrm{S}(\mathrm{mg} / \mathrm{L})$ & 0.180 & 0.179 & 0.178 & 0.181 & 0.179 & 0.164 & 0.194 & 0.184 & 0.193 & 0.194 & 0.174 & 0.155 \\
\hline \multicolumn{13}{|c|}{ 11. Element metal (Metal elements): } \\
\hline $\mathrm{Pb}(\mathrm{mg} / \mathrm{L})$ & 0.134 & 0.108 & 0.065 & 0.099 & 0.117 & .. & 0.103 & 0.042 & 0.066 & -. & & \\
\hline $\mathrm{Hg}(\mathrm{mg} / \mathrm{L})$ & 0.006 & 0.008 & 0.005 & 0.012 & 0.011 & .. & 0.015 & 0.009 & 0.011 & -. & -. & \\
\hline $\mathrm{Cd}(\mathrm{mg} / \mathrm{L})$ & 0.0 .54 & 0.045 & 0.094 & 0.053 & 0.047 & & 0.011 & 0.003 & 0.004 & .. & .. & .. \\
\hline $\mathrm{Cu}(\mathrm{mg} / \mathrm{L})$ & 0.168 & 0.047 & 0.112 & 0.068 & 0.157 & .. & 0.279 & 0.109 & 0.151 & .. & .. &.. \\
\hline $\mathrm{Al}(\mathrm{mg} / \mathrm{L})$ & 1.696 & 0.535 & 0.486 & 0.482 & 0.399 &.$\cdot$ & 1.278 & 1.160 & 1.874 & $-\cdot$ & -. & .. \\
\hline $\mathrm{Fe}(\mathrm{mg} / \mathrm{L})$ & 0.060 & 0.058 & 0.076 & 0.074 & 0.058 & 0.085 & 0.076 & 0.076 & 0.076 & 0.085 & 0.076 & 0.085 \\
\hline $\mathrm{Mg}(\mathrm{mg} / \mathrm{L})$ & (0.802 & 0.911 & 0.778 & 0.790 & 1.021 & 0.459 & 0.777 & 0.559 & 0.632 & 0.632 & 0.705 & 0.729 \\
\hline $\mathrm{Ca}(\mathrm{mg} / \mathrm{L})$ & 1.483 & 1.462 & 1.382 & 1.382 & 1.482 & 1.202 & 1.202 & 1.202 & 0.960 & 0.960 & 1.122 & 1.202 \\
\hline
\end{tabular}

Catatan (Remarks):

\begin{tabular}{|c|c|c|c|}
\hline $01=$ Lampor & $0.5=$ Jeliti & $0 \leqq=$ L.Golf & $\mathrm{ud}=$ tidak terukur (uncletected) \\
\hline $02=K \cdot 25$ & $06=$ Mempayau & $10=$ Tilang & - = tidak diambil sampel (no sample) \\
\hline $03=\mathrm{TS} \cdot 136$ & $07=$ Air Mang & $11=\mathrm{TS}-12 \mathrm{~A}$ & \\
\hline $1=$ Pemali & $08=$ Air Keroh & $12=\mathrm{TK}-13$ & \\
\hline
\end{tabular}


Tabel 6. Jenis-jenis ikan yang ada di lokasi penelitian.

Table 6. Fish species caught in the research locations.

\begin{tabular}{|c|c|c|}
\hline No. & $\begin{array}{l}\text { Kolong-kolong } \\
\text { Pool }\end{array}$ & $\begin{array}{l}\text { Jenis ikan yang tertangkap } \\
\text { Fish species caught }\end{array}$ \\
\hline 1. & Lampor & $\begin{array}{l}\text { belida (featherback) (1); baung (catfish) (2); gabus (murrel) (2); } \\
\text { lele (catfish) (2); gurame (gouramy) (2) }\end{array}$ \\
\hline 2. & $K .25$ & - \\
\hline 3. & TS-136 & $\begin{array}{l}\text { bulan (1); belida (featherback) (2); gurame (gouramy) (2); baung } \\
\text { (catfish) (2) }\end{array}$ \\
\hline 4. & Pemali & gurame (gouramy') (2); belida (featherback) (2); bulan(2) \\
\hline 5 . & Jeliti & $\begin{array}{l}\text { mas (common carp) (2); nila (nile) (2); mujair (2); gurame } \\
\text { (gouramy) (2); sengkareng (1) }\end{array}$ \\
\hline 6. & Mempayau & sepatung(1); gabus (murrel) (1); sepat siam (spotted gouram!r) (1) \\
\hline 7. & Air Mang & betok(1), sepatung( 1$)$ \\
\hline 8. & Air Keroh & betutu (sand goby') (2); gabus (murrel) (2); nila (nile) (1) \\
\hline 9. & L. Golf L. & betutu (sand goby) (2); sepatung(1) \\
\hline 10. & 'Tilang & nila (nile) (1), sepatung $(2)$ \\
\hline 11. & TS-12A & nila (nile) (1) \\
\hline 12. & TK-13 & sepatung (1); gabus (murrel) (2); nila (nile) (1) \\
\hline
\end{tabular}

Catatian (Rimaiks):

$(1)=$ tertangkap dari kolong yang bersangkutan pada waktu survai (catched from pool during surur)

$(2)=$ informasi dari penduduk sekitar kolong (information from nearby village)

wawancara dengan nelayan yang tinggal dekat kolong tersebut pernah tertangkap jenis ikan gurame. belida dan ikan bulan dengan alat tangkap jaring insang. Kolong Jeliti menurut keterangan Dinas Perikanan Tingkat II Sungai Liat Bangka pernah ditebar jenis ikan mas (Cyprinus carpio). nila (Oreochromis niloticus), mujair (O. mosambicus) dan gurame (Osphronemus gouramy). Namun dari hasil penangkapan hanya terdapat jenis ikan sengkareng (Labeobarbus tambra).

Jenis-jenis ikan yang terdapat pada kolongkolong pengamatan di Pulau Belitung adalah ikan sepatung (Pristolepis fasciatus), gabus (Ophiocephalus striatus), betok (Anabas testudineus). sepat siam (Trichogaster pectoralis), betutu (Oxyeleotris marmorata) dan ikan nila (Oreochromis niloticus).

Organisme dasar yang diambil dengan menggunakan Ekman Dredge tidak ditemukan satu jenis pun. Jenis-jenis plankton pada kolong-kolong dapat dilihat pada Tabel 7 dan untuk jenis-jenis tumbuhan air dapat dilihat pada Tabel 8. Dari jumlah fitoplankton yang terindentifikasi, kolongkolong pengamatan termasuk dalam klasifikasi tingkat kesuburan rendah (Wetzel, 1975).
Sedangkan untuk tumbuhan air ditemukan jenisjenis tumbuhan yang toleran terhadap air masam (Pancho \& Soerjani, 1983).

\section{PROSPEIK UNTUK USAHA PERIKANAN}

Pada perairan kolong-kolong bekas galian tambang timah di Bangka dan Belitung ditinjau dari beberapa parameter kualitas airnya terdepat parameter yang mendukung dan parameter yang tidak mendukung untuk budi daya ikan. Parameter yang mendukung adalah suhu, kecerahan. kedalaman, $\mathrm{pH}$ (untuk sebagian kolong), oksigen terlarut, $\mathrm{CO}_{2}$-bebas dan kandungan khlorofil-a. Parameter yang kurang mendukung karena kadarnya vang tidak sesuai dengan kebutuhan untuk kehidupan ikan dan jasad-jasad renik lainnya di dalam kolong-kolong yang diamati adalah parameter yang menentukan kesuburan perairan, yaitu alkalinitas, kesadahan, total nitrogen. fosfat $(\mathrm{PO})$, sulfat $\left(\mathrm{SO}_{1}\right)$, kalsium ( $\mathrm{Ca}_{\mathrm{l}}$ ) dan magnesium (Mg).

Adanya kedua kelompok parameter tersehu diartikan bahwa ikan dapat hidup namun untuk tumbuh dan berkembang biak diduga sulit kal'(1)a keterbatasan unsur-unsur hara yang ada dalam perairan. 
Tabel 7. Jenis-jenis plankton (individu/L) di kolong-kolong pengamatan.

Table 7. Plankton composition (individu/L) in the mining pools.

\begin{tabular}{|c|c|c|c|c|c|c|c|c|c|c|c|c|c|c|}
\hline \multirow[b]{2}{*}{ No. } & \multirow{2}{*}{$\begin{array}{c}\text { Organisme } \\
\text { Organism }\end{array}$} & \multirow{2}{*}{$\begin{array}{l}\text { Famili } \\
\text { Family }\end{array}$} & \multicolumn{12}{|c|}{ Kolong-kolong (Mining pools) } \\
\hline & & & 1 & 2 & 3 & 4 & 5 & 6 & 7 & 8 & 9 & 10 & 11 & 12 \\
\hline
\end{tabular}

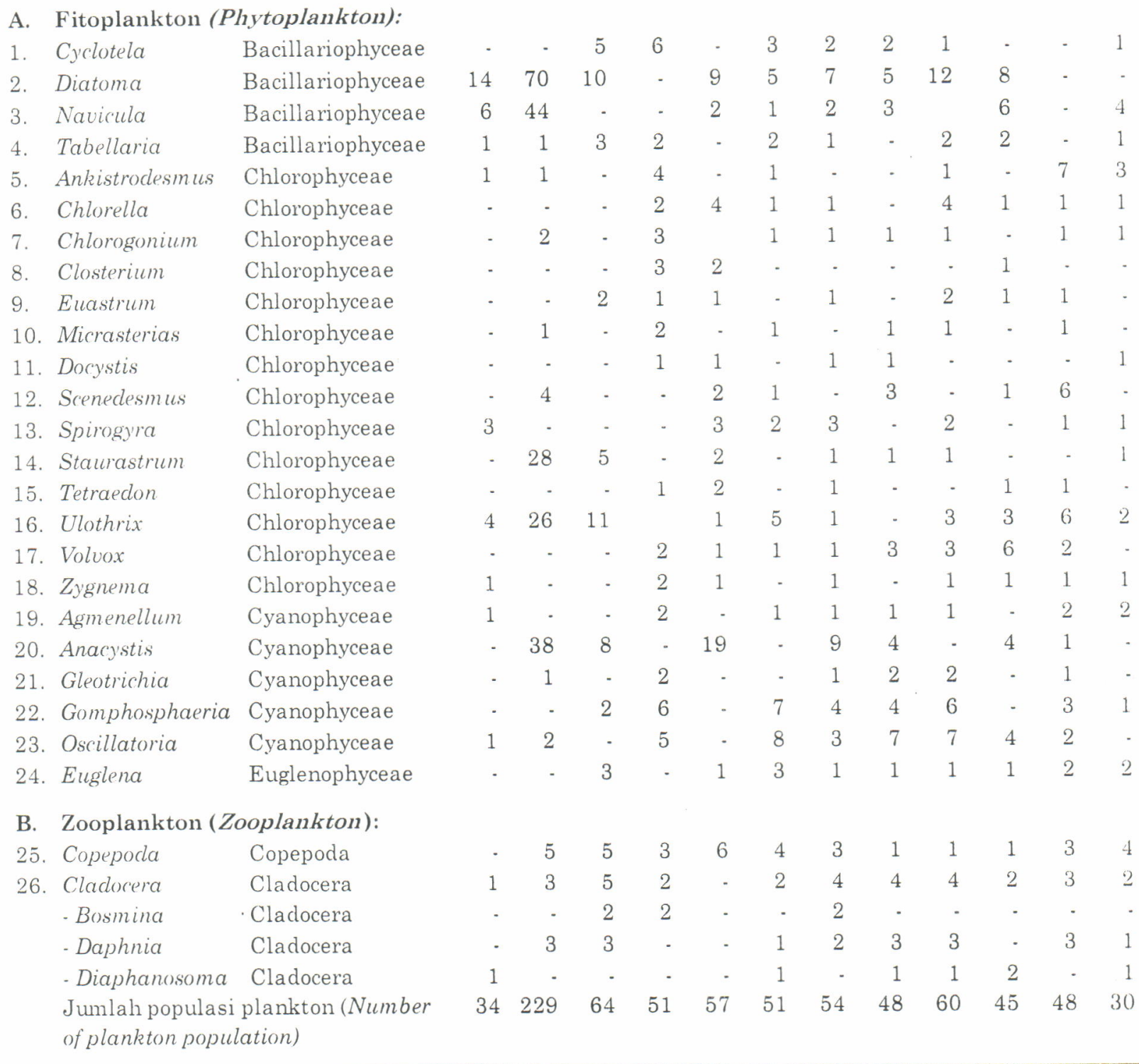

Catatan (Kemarks):

$01=1$ ampor, (02 = K.25.03 = TS-136, 04 = Pemali, $05=$ Jeliti, $06=$ Mempayau, $07=$ Air Mang, $08=$ Air Keroh. $09=\mathrm{L}$. Colf, $10=$ Thilang, $11=$ TS $12 \mathrm{~A}$ dan $12=$ TK -13 . 


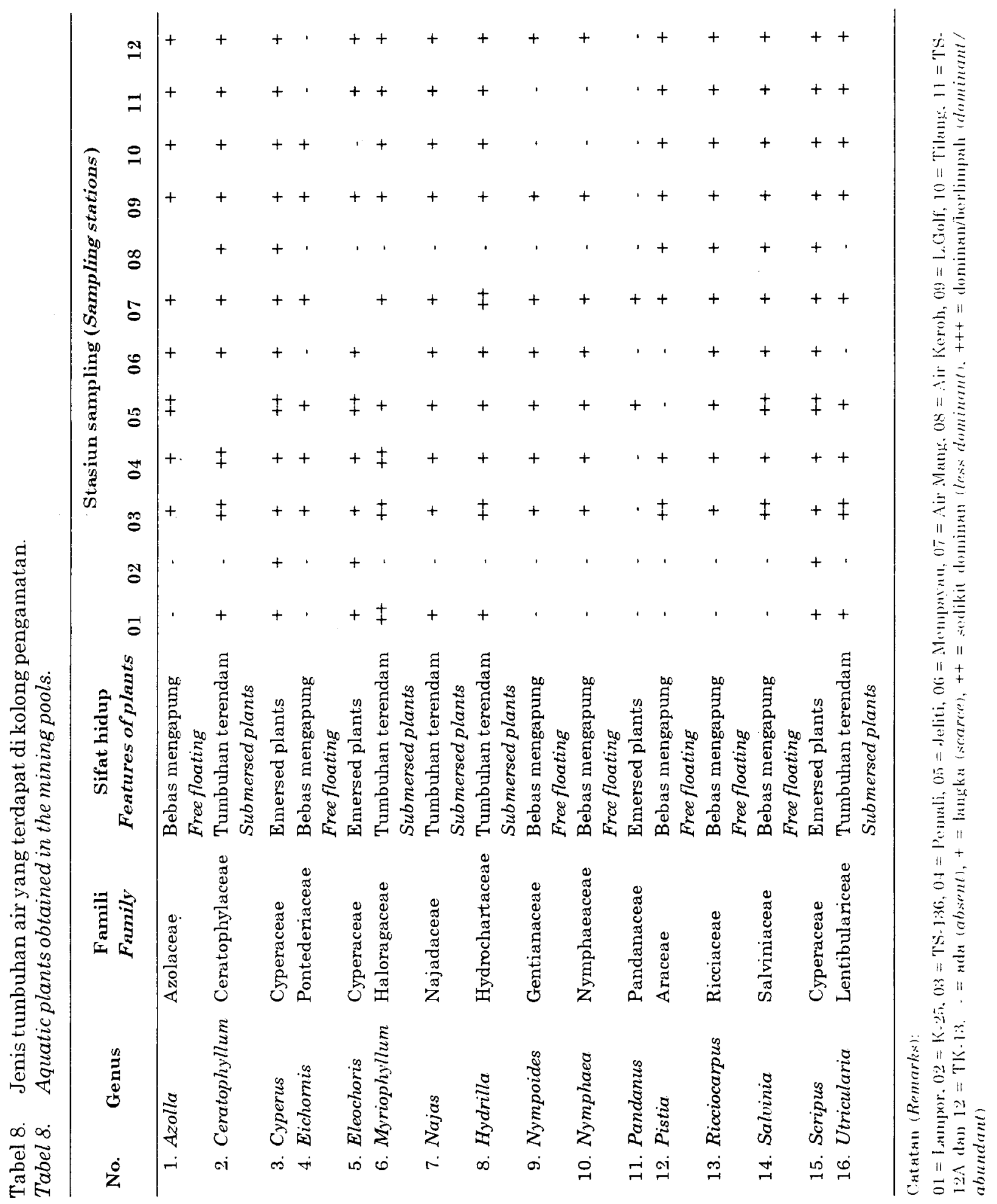


Untuk perairan dengan kondisi demikian ada dua alternatif pemecahan masalahnya, yaitu 1) air perlu dilakukan pengapuran dan pemupukan sesuai dengan kadar unsur hara yang tersedia, kemudian dilakukan penebaran; 2) diterapkan budi daya ikan dalam ruang gerak terbatas dengan membuat perlakuan-perlakuan. Dari perlakuanperlakuan akan diperoleh hasil sampingan yaitu dampak positif dari kegiatan pemberian pakan dan pupuk di mana pakan yang tidak termanfaatkan akan menambah dan meningkatkan unsur-unsur hara ke dalam perairan, sehingga perairan diharapkan akan meningkat kesuburannya dan selanjutnya dapat ditebar dengan beberapa jenis ikan terutama jenis-jenis ikan herbivor dan omnivor seperti gurame, nila, mujair dan ikan mas. Prospek pengembangan perikanan pada kolong-kolong dengan cara ke dua ini lebih menjanjikan dan diduga memberikan prospek yang menguntungkan bagi masyarakat sekitar kolong. Cara pengembangannya dapat berupa pemeliharaan ikan dalam sangkar-sangkar atau jaring-jaring terapung.

\section{KESIMPULAN}

Analisis beberapa parameter fisika-kimia tanah dasar dan bagian tepi dari kolong-kolong yang diamati menunjukkan bahwa pada umumnya tingkat kesuburannya rendah (kandungan unsur hara rendah, namun dalam beberapa hal kolong. kolong lama sudah kelihatan lebih baik meskipun masih dalam kategori dengan tingkat kesuburan tanah rendah).

Hasil analisis dan pengukuran parameter biolimnologi perairan, beberapa parameter kualitas air seperti suhu, kecerahan, kedalaman, $\mathrm{pH}$, oksigen dan karbondioksida menunjukkan bahwa kondisi perairan pada kolong muda dan tua layak untuk hidup ikan. Beberapa parameter kesuburan seperti alkalinitas, kesadahan, total nitrogen, fosfat, sulfat, kalsium dan magnesium menunjuk- kan klasifikasi perairan dengan tingkat kesuburan rendah.

Kandungan logam berat pada bagian dasar kolong-kolong cukup tinggi, sehingga kegiatan perikanan pada lapisan air di bagian permukaan seperti kegiatan keramba jaring apung lebih baik diterapkan dibandingkan dengan kegiatan introduksi ikan langsung ke perairan. Prospek pengembangan perikanan pada kolong-kolong bekas penambangan timah lebih baik dengan cara memelihara ikan dengan menggunakan sistem karamba, jaring dan sangkar terapung.

\section{DAFTAR PUSTAKA}

APHA. 1981. Standard methods for the examination of water and waste water. $15^{\text {th }}$ edition. American. Public Health Association. Washington, DC. 1134 pp.

Anonim. 1991. Studi evaluasi lingkungan unit penambangan dan peleburan timah Bangka. Volume 2 Laporan Utama. PT Tambang Timah (Persero) Pangkalpinang, Bangka. 332 hal.

Boyd, C.E. 1979. Water Quality in Warmwater Fishponds. Auburn University, Departement of Fisheries and Allied Aquacultures. First Edition. Alabama, USA. 359 pp.

Cuchlaine, A.H. 1975. Introduction to Physical and Biological Oceanography. Edward Arnold Publisher Ltd., London. 372 pp.

NTAC. 1968. Water Quality Criteria. FWPCA. Washington D.C. $234 \mathrm{pp}$

Pancho, J.V. and Soerjani, M. 1983. Aquatic Weeds of Southeast Asia. BIOTROP, SEAMEO, Regional Centre for Tropical Biology, Bogor, Indonesia. 130 $\mathrm{pp}$.

Parma, S. 1980. The History of eutrofication concept and the eutropication in the Netherlands. Hydrobiological Bulletin. 14(1): 5-21.

Pescod, M.B. 1973. Investigation of Rational Effluent and Stream Standards for Tropical Countries. A.I.T., Bangkok. 59 pp.

Swingle, H.S. 1968. Standardization of chemical analysis for waters and pond muds. F.A.O. Fisheries Report. 44(4): 397-407.

Wetzel, R.G. 1975. Limnology. Saunders College Publishing. Philadelphia. 743 pp. 